\title{
Ronald Epstein: from awkward moments to mindful practice
}

Cite as: CMAJ 2018 November 19;190:E1365-6. doi: 10.1503/cmaj.180821

CMAJ Podcasts: author interview at https://soundcloud.com/cmajpodcasts/180821-pro

$\mathrm{n}$ his practice at the University of Rochester Medical Center in upstate New York, Dr. Ronald Epstein has a habit of pausing for a few seconds before entering a patient's room. Keeping his hand on the doorknob, he prepares to be fully present for the patient by taking a breath and consciously setting aside thoughts of other things. He's done this small act for years, but he didn't always speak about it. Today, Epstein is known as the guru of mindfulness in medicine.

As an academic studying doctorpatient communication in the mid-1990s, Epstein taped primary care doctors to find out how they assessed risks for HIV. One took a second to ask if a patient practised safe sex, and then quickly moved on, apparently too embarrassed to probe further. Another inquired about sexual behaviour while simultaneously palpating a man's genitals for a physical examination. "If you really wanted to get highquality information, that's not the time to do it," Epstein said wryly.

Shocked by his research videos, he soon learned that the taped doctors were as surprised as he was, and some became visibly disturbed when they viewed themselves. By the time his results were published, ${ }^{1}$ he had switched direction and was strategizing about how to make doctors more aware of what they're doing with a patient in the moment. It was a project that became his life's work.

Ensconced in the New York suburbs for high school, he'd tried to escape a culture that felt to him "extremely superficial and materialistic" by enrolling in a one-day course on transcendental meditation, but he thought it was a fad. Then a friend taught him the basics of Zen meditation,

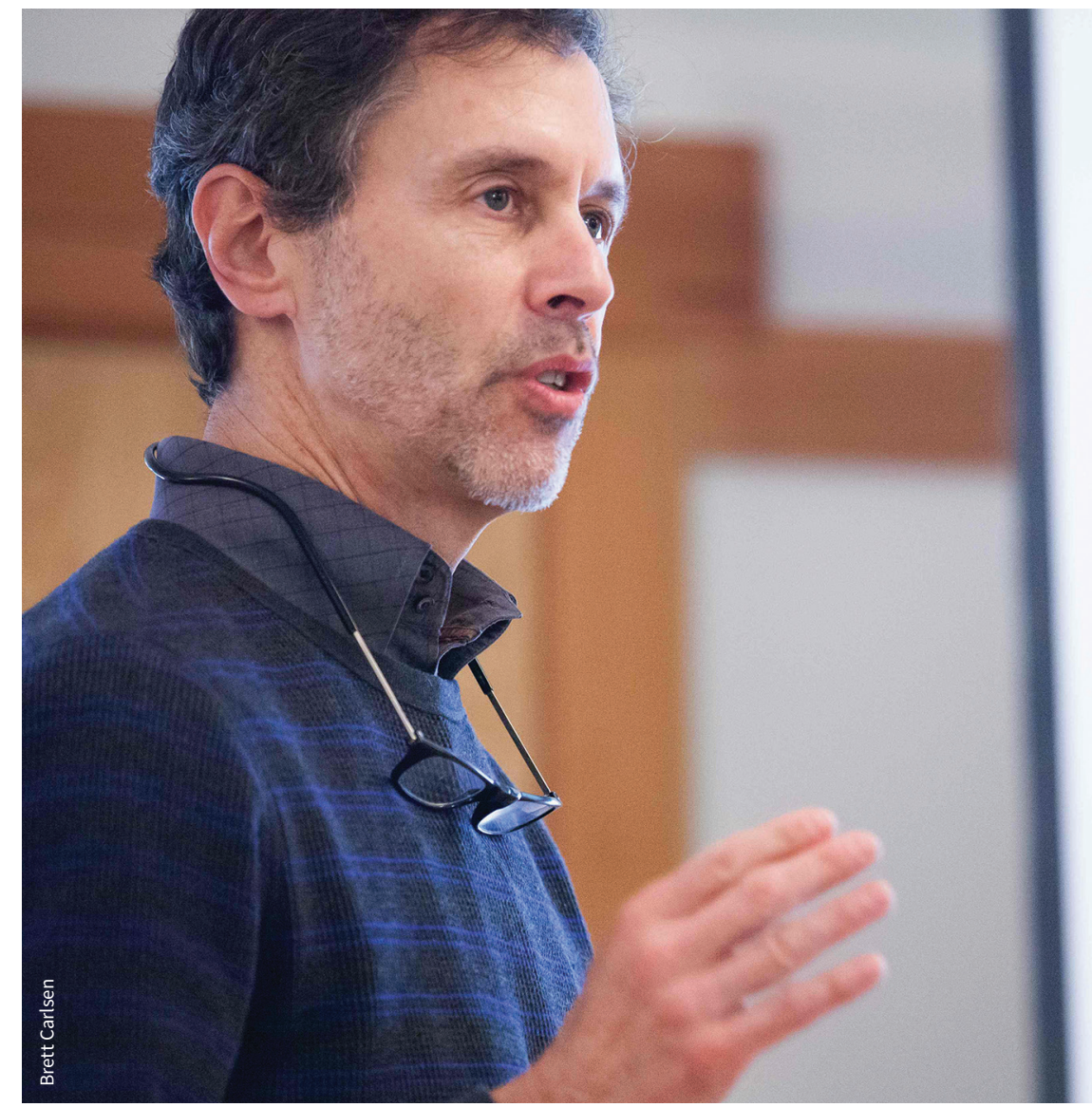

Meditation is "part of my marrow," said Dr. Ron Epstein.

and it stuck. Enthralled by the work of Zen master Shunryu Suzuki, he spent a semester during university living at the monastery Suzuki established near San Francisco and even briefly considered becoming a monk. But he returned to Wesleyan University in Connecticut and completed his degree in music, entering medical school several years later.

When people ask if meditation has changed him, he tells them he can't answer that question because he wasn't full-grown when he started practising. "It's part of my marrow," he said. "It's part of who I am." He's fully present while meditating, he said, just as he is when playing the harpsichord. "Musicians know about presence and its absence," he writes in his 2017 book, Attending: Medicine, Mindfulness, and Humanity. "When you're caught up in your thoughts and just going through the motions, your professional colleagues will say you're 'just phoning it in.'”' 
Epstein is also a student of Chinese medicine and volunteered in a local acupuncture clinic during medical school. Later, he learned "enough Chinese to get by," then went to Hangzhou for a threemonth Chinese medicine course.

When he started his inquiry into how to help doctors be present with their patients, he teased apart the specific actions involved in meditating or making music. Then he whittled down his ideas, turning them into a list of attributes that can distinguish a technically competent clinician from what he terms "a doctor that I'd really want to have as my own doctor." He was on a deadline: the Journal of the American Medical Association (JAMA) had a call out for papers on medical education, and he aimed to convince its editors that what he was calling mindful practice could be taught, or at least modelled for medical students and residents.

Charlene Breedlove is JAMA's poetry editor - the New Yorker has called her the "grande dame of medical poetry" 3 - but she was also editor of the journal's medical education issue and she'd always been sympathetic to Zen practices, she said. She pushed Epstein through multiple drafts, asking him to condense and clarify along the way. To list out characteristics of mindful practice, he used the classic table form so familiar to readers of medical journals. Active observation of oneself, the patient and the problem was one characteristic; another was curiosity about the unknown. He offered explanation in the text, spelling out the characteristic "adoption of a beginner's mind," a Zen phrase that means allowing for new possibilities, by contrasting it to the expert's mind, a reliance on past experi- ence to develop diagnostic and therapeutic options. He would later say he had written "a kind of manifesto."

"Mindful Practice" was published in September 1999, ${ }^{4}$ and Epstein received hundreds of letters and emails in response. "Finally," he said, "I felt seen." Twenty years later, he talks about his ideas for being present as a clinician as often as he can. And even after publishing his popular 2017 book, copyrighting a program on practising mindfully that he teaches with colleagues from Rochester (www.urmc. rochester.edu/family-medicine/mindful -practice/presentations-workshops.aspx), and delivering grand rounds and workshops at medical centres around the world, including BC Children's Hospital in Vancouver in February 2018, and Mount Sinai Hospital in Toronto in June 2018, he credits the 1999 article with changing his life. His writing sometimes has that effect on others.

Dr. Jen Williams, of Kelowna General Hospital in British Columbia's Okanagan Valley, started reading Epstein's Attending soon after it came out. Though she practised meditation regularly, the full-time emergency physician and mother of two small boys often felt harried as she began her shifts in the emergency department. So she started keeping Epstein's book in her locker, arriving at the hospital early and reading a page or two, followed by a few minutes of meditation, before stepping into the emergency department. It was her own doorknob moment, and Epstein's book played a crucial role, she said, by offering clinicians "permission to feel and be human and not have to shut ourselves down and keep our emotions in a box." For Williams, Epstein's take-home message is that when she picks up an abused baby and feels that its arm is broken, it's okay for her to be upset. "You can take a moment to feel and experience those emotions and then let them go, so that you can keep working," she said. "And then you can come back to them and reflect on them in time."

This year, Williams has made a personal effort to spread Epstein's ideas as a way of casting out old-school notions of the doctor as diagnostician or automaton. In February, she presented a grand rounds on his book to residents in the University of British Columbia multisite emergency medicine residency program, and this spring she gave each of the emergency medicine residents at Kelowna General a copy of the book to dip into on their retreat. Epstein may have spearheaded the movement to incorporate mindfulness into medical practice, but it's physicians such as Williams who are taking the precepts of mindful practice into the trenches.

\section{Miriam Shuchman MD}

Department of Psychiatry, University of Toronto, Toronto, Ont.

\section{References}

1. Epstein RM, Morse DS, Frankel RM, et al. Awkward moments in patient-physician communication about HIV risk. Ann Intern Med 1998;128: 435-42.

2. Epstein R. Attending: medicine, mindfulness, and humanity. New York: Scribner; 2017.

3. Gee A. Ode on a stethoscope. The New Yorker 2015 Jan. 14. Available: www.newyorker.com/ tech/elements/ode-stethoscope (accessed 2018 June 20).

4. Epstein RM. Mindful practice. JAMA 1999;282: 833-9.

This article was solicited and has not been peer reviewed. 